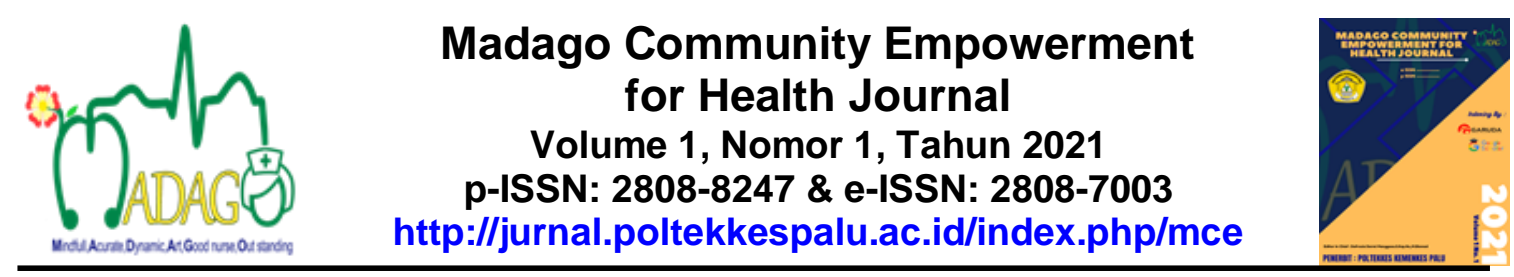

\title{
Edukasi Pencegahan Anemia Pada Ibu Hamil
}

\author{
Anemia Prevention Education among Pregnant Women

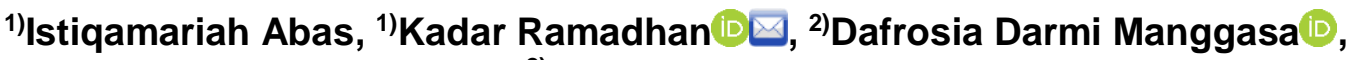 \\ 2)Nirva Rantesigi \\ 1)Program Studi D-III Kebidanan Poso, Poltekkes Kemenkes Palu \\ 2) Program Studi D-III Keperawatan Poso, Poltekkes Kemenkes Palu \\ 『mail : kadarlaure@gmail.com
}

\begin{abstract}
ABSTRAK
Anemia yang terjadi pada ibu hamil dapat meningkatkan risiko komplikasi serius, sehingga harus dicegah sedini mungkin. Kegiatan ini bertujuan untuk meningkatkan pengetahuan ibu hamil tentang anemia. Metode kegiatan ini berupa penyuluhan yang diberikan kepada seorang ibu hamil di Kelurahan Lawangan. Kegiatan ini dilaksanakan pada tanggal 14 September 2021. Kegiatan diawali dengan pemberian pretest, kemudian dilanjutkan dengan penyuluhan menggunakan media leaflet. Kegiatan diakhiri dengan pemberian posttest. Hasil kegiatan menunjukan terdapat peningkatan pengetahuan ibu tentang anemia dari $50 \%$ sebelum penyuluhan menjadi $90 \%$ setelah penyuluhan. Kami menyarankan agar ibu hamil dapat melakukan pencegehan anemia seperti mengonsumsi makanan sumber besi serta perlu melakukan tes kadar hemoglobin darah.
\end{abstract}

Kata Kunci: edukasi; anemia; ibu hamil.

\begin{abstract}
Anemia that occurs in pregnant women can increase the risk of serious complications, so it must be prevented as early as possible. This activity aims to increase the knowledge of pregnant women about anemia. The method of this activity is in the form of counseling given to a pregnant woman in Lawangan Village. This activity was carried out on September 14, 2021. The activity began with giving a pretest, then continued with counseling using leaflet media. The activity ended with giving a posttest. The results of the activity showed that there was an increase in maternal knowledge about anemia from $50 \%$ before counseling to $90 \%$ after counseling. We suggest that pregnant women can prevent anemia such as consuming iron-rich foods and need to do a blood hemoglobin level test.
\end{abstract}

Keywords: education; anemia; pregnant women

Copyright (c) 2021

DOI: http://doi.org/10.33860/mce.v111.662

Received: 19-10-2021; Accepted: 31-10-2021; Published: 31-10-2021

\section{PENDAHULUAN}

Kebutuhan zat besi meningkat selama kehamilan untuk memenuhi peningkatan kebutuhan fetoplasenta, untuk meningkatkan massa eritrosit ibu, dan untuk mengkompensasi kehilangan zat besi saat melahirkan. Di lebih dari $80 \%$ negara di dunia, prevalensi anemia pada kehamilan $>20 \%$ dan dapat dianggap sebagai masalah kesehatan masyarakat yang utama. Prevalensi global anemia pada kehamilan diperkirakan sekitar 41,8\% (Garzon et al., 2020). Wanita hamil yang mengalami kekurangan besi menunjukkan berbagai gejala, termasuk pucat, sesak napas, jantung berdebar, rambut rontok, sakit kepala, vertigo, kram kaki, pusing, dan mudah marah. Kekurangan besi juga dapat menyebabkan penurunan termoregulasi, kelelahan, 
konsentrasi yang buruk, penurunan kapasitas kerja, penurunan produksi ASI ibu, dan penipisan simpanan besi ibu selama periode postpartum (American College of Obstetricians and Gynecologists, 2012; Annamraju \& Pavord, 2016). Selanjutnya, risiko depresi postpartum meningkat secara signifikan dibandingkan dengan ibu hamil tanpa kekurangan zat besi; kelelahan dan depresi, karena anemia, dapat mempengaruhi hubungan ibu-anak menjadi kurang baik (Bruno et al., 2018; Vitale et al., 2016; Yılmaz et al., 2017)

Anemia pada ibu hamil disebabkan oleh kekurangan dan asupan makanan yang rendah, serta dapat juga disebabkan oleh ketidaktahuan tentang pola makan yang benar. Zat besi diperlukan otak bayi untuk berkembang sejak dini. Kekurangan zat besi sebelum kehamilan, jika tidak diatasi, dapat menyebabkan anemia pada ibu hamil (Parulian \& Roosleyn, 2016). Kondisi anemia dapat meningkatkan risiko kematian ibu saat melahirkan, melahirkan bayi dengan berat badan lahir rendah, janin dan ibu rentan terhadap infeksi, keguguran dan peningkatan bayi prematur (Sukmawati, Mamuroh, \& Nurhakim, 2019).

Anemia lebih sering terjadi selama kehamilan karena kebutuhan nutrisi meningkat dan perubahan dalam darah dan sumsum tulang terjadi selama kehamilan (Leny, 2019). Penyebab utama anemia adalah kekurangan zat besi di semua negara, terutama di negara berkembang. Hal ini disebabkan oleh asupan zat besi yang tidak memadai, asupan zat besi yang tinggi selama kehamilan, kehilangan zat besi melalui perdarahan, atau penyakit infeksi (Amanupunnyo, Shaluhiyah, \& Margawati, 2018). Ibu hamil primigravida yang mengalami anemia kehamilan sebesar $44,6 \%$ sedangkan ibu multigravida yang mengalami anemia kehamilan sebesar $12,8 \%$. Hal tersebut disebabkan ibu primigravida belum mempunyai pengalaman untuk menjaga kesehatan kehamilan dari kehamilan sebelumnya karena baru pertama kali hamil (Yanti, Sulistianingsih, \& Keisnawati, 2015).

Pengetahuan merupakan salah satu faktor yang menstimulasi atau merangsang kinerja suatu perilaku kesehatan. Ketika ibu hamil mengetahui dan memahami akibat dari anemia dan cara pencegahannya, maka mereka akan berperilaku baik dengan harapan dapat terhindar dari berbagai akibat atau resiko dari anemia kehamilan. Perilaku kesehatan tersebut berdampak pada penurunan kejadian anemia pada ibu hamil (Purbadewi, Noor, \& Ulvie, 2013).

Asupan vitamin $\mathrm{C}$ mendukung penyerapan zat besi dalam tubuh ibu hamil. Adanya zat penghambat atau inhibitor penyerapan zat besi yang biasa dikonsumsi ibu hamil, seperti kafein, tanin (dalam teh), oksalat, fitat, dapat menghambat penyerapan zat besi dalam tubuh dan menyebabkan anemia defisiensi besi (Purwaningtyas \& Prameswari, 2017). Anemia tidak hanya mempengaruhi ibu, kemungkinan besar bayi dari ibu yang kekurangan zat besi atau anemia memiliki sedikit atau tidak ada simpanan zat besi di dalam tubuhnya, bahkan jika mereka tidak menderita anemia. Hal ini dapat menyebabkan gangguan fungsi kognitif pada masa remaja dan dewasa (Tanziha, Damanik, Utama, \& Rosmiati, 2016). Tujuan dari kegiatan ini adalah meningkatkan pengetahuan ibu hamil tentang anemia di Kelurahan Lawanga. 


\section{METODE}

Kegiatan penyuluhan ini dilakukan di kelurahan Lawanga pada tanggal 14 September 2021. Sasaran dalam kegiatan pengabdian ini adalah seorang ibu hamil. Kegiatan ini merupakan bagian dari Praktik Keluarga Binaan Prodi D-III Kebidanan Poso. Kegiatan pengabdian masyarakat dimulai dengan sosialisasi kegiatan kemudian dilanjutkan dengan pembagian kuesioner (pre-test) dan memberi waktu kepada ibu untuk menjawab, setelah membagikan leaflet kepada responden lalu melakukan penyuluhan tentang pencegahan anemia pada ibu hamil bagi ibu hamil yang di dalamnya membahas tentang pengertian anemia, penyebab anemia, dan pencegahan anemia, kemudian membagikan kuesioner (post-test) untuk mengevaluasi pengetahuan ibu setelah dilakukan penyuluhan.

\section{HASIL DAN PEMBAHASAN}

Penyuluhan tentang Anemia yang dilakukan di Kelurahan Lawanga, sebelum dilakukan penyuluhan ibu hamil belum terlalu paham mengenai anemia pada kehamilan maka dari itu kami melakukan penyuluhan tentang Anemia agar ibu hamil lebih memahami tentang pentingnya menjaga nutrisi agar terhindar dari anemia saat hamil.

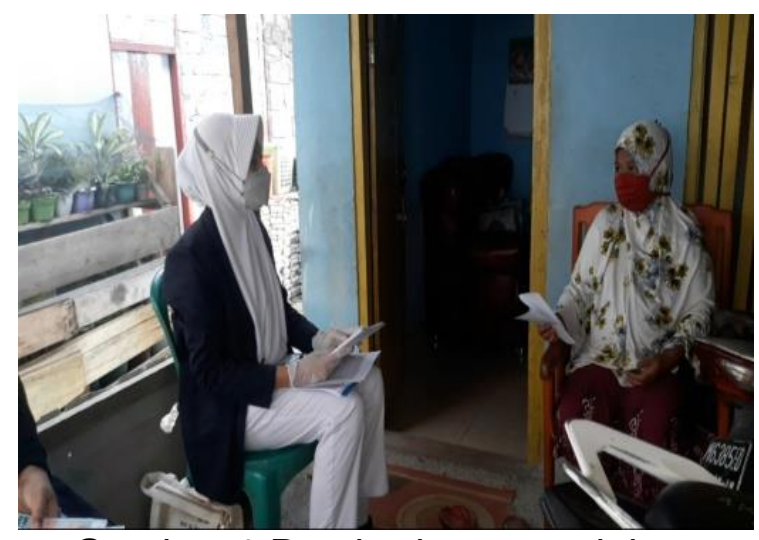

Gambar 1 Pemberian penyuluhan

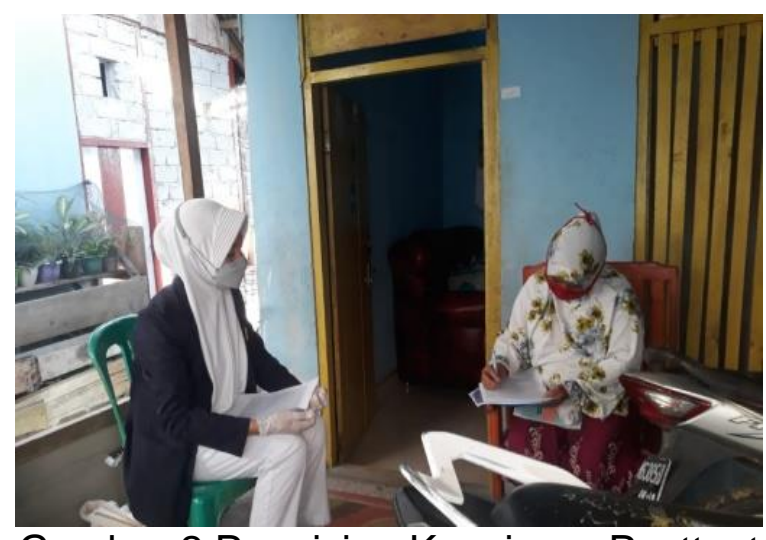

Gambar 2 Pengisian Kuesioner Posttest

Penyuluhan yang dilakukan di rumah responden Kelurahan Lawanga tentang Anemia Pada ibu hamil. Ibu hamil sebagai responden sehingga diperoleh hasil terdapat peningkatan sebelum dan setelah dilakukan penyuluhan hasil tersebut terlihat pada grafik dibawah ini: 


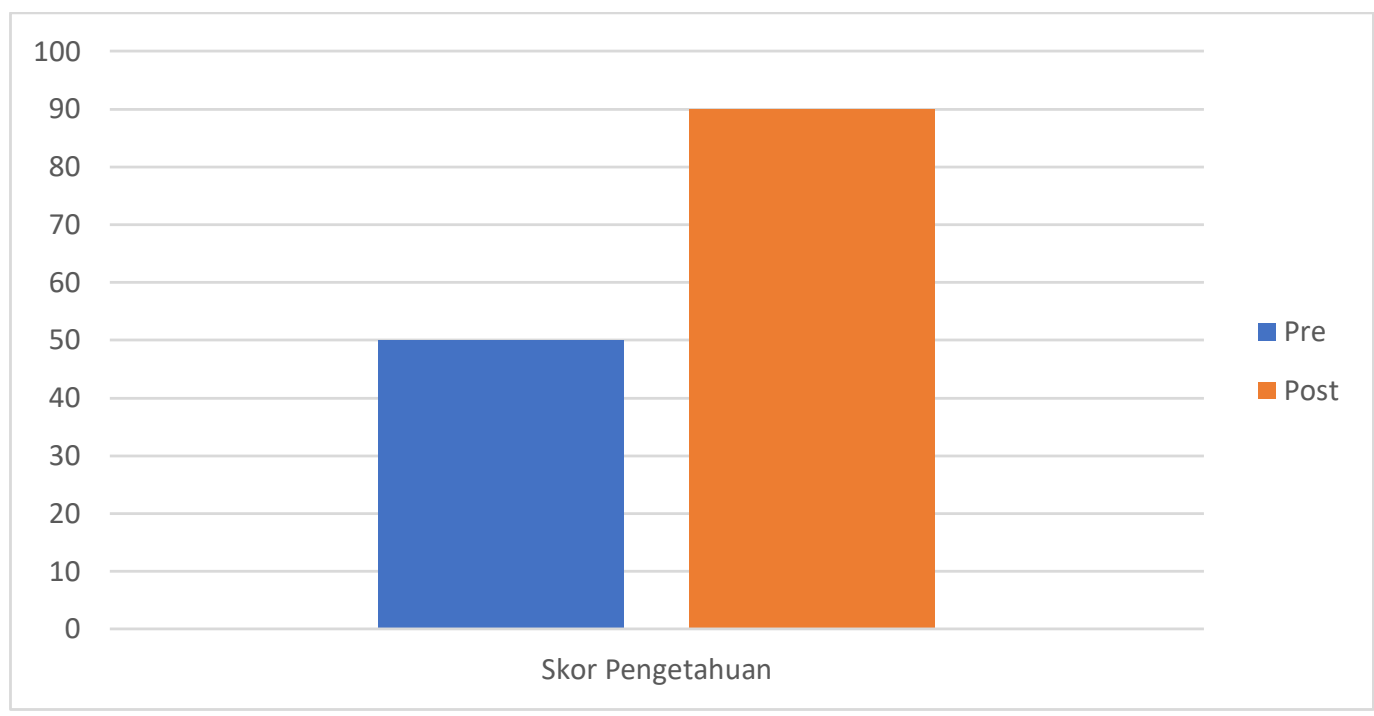

Gambar 3 Grafik Peningkatan pengetahuan

Berdasarkan penelitian sebelumnya, $2 / 3(75 \%)$ ibu hamil masih menganggap anemia pada kehamilan merupakan hal yang alamiah selama kehamilan berlangsung (Nurfatimah, Fiarsi, Longgupa, \& Ramadhan, 2020), oleh karena itu, pentingnya edukasi kepada ibu hamil tentang pencegahan anemia sangat perlu. Pencegahan anemia merupakan hal yang penting dilakukan dalam 1000 Hari Pertama Kehidupan (HPK). Banyaknya dampak yang ditimbulkan akibat ibu hamil menderita anemia bukan hanya berdampak pada ibu, namun juga pada anak, salah satunya adalah BBLR yang dapat menyebabkan stunting (Nurfatimah et al., 2021).

Berdasarkan grafik di atas terlihat perubahan pengetahuan ibu tentang Anemia, Perubahan pengetahuan ibu sebelum dan setelah penyuluhan sangat terlihat, ibu sudah mulai paham tentang anemia pada kehamilan dan diharapkan ibu lebih memahami apa dampak jika tidak mengetahui tentang anemia pada ibu hamil. Hal lain yang penting adalah konsumsi makanan yang harus dperhatikan. Memperbanyak konsumsi makan sumber zat besi dan asam folat seperti tahu dan tempe dan makan mengandung vitamin $\mathrm{C}$ seperti jus tomat sangat baik untuk meningkatkan kadar hemoglobin dalam darah (Elviyaningsih, Rafika, \& Putu Candriasih, 2020; Suastira, Sumiaty, \& Ansar, 2020; Wulan, Juliana, Arma, \& Syari, 2021).

\section{SIMPULAN DAN SARAN}

Berdasarkan hasil pelaksanaan kegiatan, dapat disimpulkan bahwa terdapat peningkatan pengetahuan ibu hamil mengenai anemia pada kehamilan dari sebelum dan setelah penyuluhan. Diharapkan agar ibu hamil dapat melakukan pencegehan anemia seperti mengonsumsi makanan sumber besi serta perlu melakukan tes kadar hemoglobin darah.

\section{UCAPAN TERIMA KASIH}

Kami menyampaikan terima kasih kepada Bidan Kelurahan Lawanga yang telah memberikan izin dan membantu sehingga kegiatan ini dapat terlaksanan dengan baik 


\section{DAFTAR PUSTAKA}

Amanupunnyo, N. A., Shaluhiyah, Z., \& Margawati, A. (2018). Analisis Faktor Penyebab Anemia pada Ibu Hamil di Puskesmas Kairatu Seram Barat. Jurnal Aisyah: Jurnal IImu Kesehatan, 3(2), 173-181. Retrieved from https://aisyah.journalpress.id/index.php/jika/article/view/A_S_M

American College of Obstetricians and Gynecologists. (2012). Management of preterm labor. Obstetrics \& Gynecology, 119(6), 1308-1317. Retrieved from http://journals.Iww.com/00006250-201206000-00049

Annamraju, H., \& Pavord, S. (2016). Anaemia in pregnancy. British Journal of Hospital Medicine, 77(Sup10), 584-588. Retrieved from http://www.magonlinelibrary.com/doi/10.12968/hmed.2016.77.10.584

Bruno, A., Laganà, A. S., Leonardi, V., Greco, D., Merlino, M., Vitale, S. G., Triolo, O., et al. (2018). Inside-out: the role of anger experience and expression in the development of postpartum mood disorders. The Journal of Maternal-Fetal \& Neonatal Medicine, 31(22), 3033-3038. Retrieved from https://www.tandfonline.com/doi/full/10.1080/14767058.2017.1362554

Elviyaningsih, S., Rafika, \& Putu Candriasih. (2020). Hubungan Umur dan Konsumsi Makanan Mengandung Zat Besi dengan Anemia pada lbu Hamil di Puskesmas Talise Palu. Jurnal Bidan Cerdas, 1(1), 1-8. Retrieved from http://jurnal.poltekkespalu.ac.id/index.php/JBC/article/view/37

Garzon, S., Cacciato, P. M., Certelli, C., Salvaggio, C., Magliarditi, M., \& Rizzo, G. (2020). Iron Deficiency Anemia in Pregnancy: Novel Approaches for an Old Problem. Oman Medical Journal, 35(5), e166-e166. Retrieved from http://omjournal.org/articleDetails.aspx?coType=1\&ald=2724

Leny. (2019). 1035325 Faktor-faktor yang Berhubungan dengan Kejadian Anemia Pada Ibu Hamil. Jurnal Kebidanan: Jurnal Medical Science IImu Kesehatan Akademi Kebidanan Budi Mulia Palembang, 9(2), 161-167. Akademi Kebidanan Budi Mulia Palembang. Retrieved from http://dx.doi.org/10.35325/kebidanan.v9i2.195

Nurfatimah, N., Anakoda, P., Ramadhan, K., Entoh, C., Sitorus, S. B. M., \& Longgupa, L. W. (2021). Perilaku Pencegahan Stunting pada Ibu Hamil. Poltekita : Jurnal IImu Kesehatan, 15(2), 97-104. Retrieved from https://jurnal.poltekkespalu.ac.id/index.php/JIK/article/view/475

Nurfatimah, N., Fiarsi, L., Longgupa, L. W., \& Ramadhan, K. (2020). Pengetahuan dan Sikap tentang Tanda Bahaya dalam Kehamilan serta Keaktifan Ibu dalam Kelas Ibu Hamil. Jurnal Sehat Mandiri, 15(1), 52-61. Retrieved from http://jurnal.poltekkespadang.ac.id/ojs/index.php/jsm/article/view/166

Parulian, I., \& Roosleyn, T. (2016). Strategi dalam penanggulangan pencegahan anemia pada kehamilan. Jurnal IImiah Widya, 3(3), 1-9. Retrieved from https://ejournal.jurwidyakop3.com/index.php/jurnal-ilmiah/article/view/255/223

Purbadewi, L., Noor, Y., \& Ulvie, S. (2013). Hubungan Tingkat Pengetahuan Tentang Anemia dengan Kejadian Anemia pada Ibu Hamil. Jurnal Gizi, 2(1), 31-39. Retrieved from https://jurnal.unimus.ac.id/index.php/jgizi/article/view/754

Purwaningtyas, M. L., \& Prameswari, G. N. (2017). Faktor Kejadian Anemia pada Ibu Hamil. Higeia Journal of Public Health Research and Development, 1(3), 84-94. Retrieved from https://journal.unnes.ac.id/sju/index.php/higeia/article/view/14291 Suastira, Sumiaty, \& Ansar. (2020). Konsumsi Pangan Sumber Zat Besi dan Asam Folat dengan Anemia pada Ibu Hamil di Puskesmas Tawaeli. Jurnal Bidan 
Cerdas,

$1(1)$

$9-15$.

Retrieved

from

http://jurnal.poltekkespalu.ac.id/index.php/JBC/article/view/40

Sukmawati, Mamuroh, L., \& Nurhakim, F. (2019). Pengaruh Edukasi Pencegahan dan

Penanganan Anemia Terhadap Pengetahuan dan Sikap Ibu Hamil. Jurnal $\begin{array}{llll}\text { Keperawatan } B S I, & 7(1), & 42-47 . & \text { Retrieved from }\end{array}$ https://ejournal.bsi.ac.id/ejurnal/index.php/jk/article/view/4689

Tanziha, I., Damanik, M. R. M., Utama, L. J., \& Rosmiati, R. (2016). Faktor Risiko Anemia lbu Hamil di Indonesia. Jurnal Gizi dan Pangan, 11(2), 143-152. Retrieved from https://journal.ipb.ac.id/index.php/jgizipangan/article/view/14687

Vitale, S. G., Laganà, A. S., Muscatello, M. R. A., La Rosa, V. L., Currò, V., Pandolfo, G., Zoccali, R. A., et al. (2016). Psychopharmacotherapy in Pregnancy and Breastfeeding. Obstetrical \& Gynecological Survey, 71(12), 721-733. Retrieved from https://journals.Iww.com/00006254-201612000-00018

Wulan, M., Juliana, S., Arma, N., \& Syari, M. (2021). Efektivitas Pemberian Tablet Fe dan Jus Tomat terhadap Peningkatan Kadar Hb pada Ibu Hamil. Jurnal Bidan $\begin{array}{llll}\text { Cerdas, 3(3), 89-95. } & \text { Retrieved from }\end{array}$ http://jurnal.poltekkespalu.ac.id/index.php/JBC/article/view/449

Yanti, D. A. M., Sulistianingsih, A., \& Keisnawati. (2015). Faktor-Faktor Terjadinya Anemia pada lbu Primigravida di Wilayah Kerja Puskesmas Pringsewu Lampung. Jurnal Keperawatan, 6(2), 79-87. Retrieved from https://ejournal.umm.ac.id/index.php/keperawatan/article/view/2862

Yılmaz, E., Yılmaz, Z., Çakmak, B., Gültekin, İ. B., Çekmez, Y., Mahmutoğlu, S., \& Küçüközkan, T. (2017). Relationship between anemia and depressive mood in the last trimester of pregnancy. The Journal of Maternal-Fetal \& Neonatal Medicine, 30(8), 977-982. Retrieved from https://www.tandfonline.com/doi/full/10.1080/14767058.2016.1194389 